\title{
EL CONTROL DEL MUNICIPIO BORBONICO. LA REFORMA MUNICIPAL DE 1747 EN ORIHUELA*
}

\author{
María del Carmen IRLES VICENTE \\ Universidad de Alicante
}

La reforma municipal que, por decreto de 4 de julio de 1747, se proyectó para la ciudad de Orihuela respondía a un planteamiento establecido años atrás y que, sin embargo, no se había puesto en práctica en la forma en que había sido pensado en sus orígenes '.

A raíz de la batalla de Almansa y consiguiente caída de las tierras valencianas en poder de Felipe V, éste decidió abolir los fueros e implantar en su lugar las leyes vigentes en Castilla; con ello pretendía uniformar los distintos reinos de la monarquía hispánica conforme al modelo castellano. Este proyecto de uniformización no llegó a consolidarse totalmente, pues cuarenta años después de que Felipe $\mathrm{V}$ expresara su deseo de "reducir todos mis Reynos de España a la uniformidad de unas mismas leyes, usos, costumbres y tribunales, gobernándose igualmente todos por las leyes de Castilla" "2, al menos dos ciudades del sur valenciano, Orihuela y Alicante, vieron cómo por sendos decretos se les volvía a encarecer se gobernasen según las leyes castellanas, a la vez que se les privaba de la autonomía que, a nivel económico, habían mantenido hasta ese momento aprovechando la indeterminación administrativa en que habían quedado sumidas tras la abolición de los fueros.

Para perfilar la actuación del Cabildo oriolano en las cuatro décadas que median entre el decreto de Nueva Planta (1707) y aquél en el cual se fija la reforma del gobierno municipal de la ciudad de Orihuela (1747), pueden ser suficientes algunos de los juicios emitidos por la Junta creada para la dotación y establecimiento de nuevo gobierno en Orihuela, quien señalaba que:

* Este trabajo ha sido realizado gracias a la concesión de una ayuda de la Consellería de Cultura, Educació i Ciència de la Generalitat Valenciana para la realización de proyectos de investigación conducentes a la obtención del grado de doctor.

1 La documentación básica para el conocimiento de los presupuestos que motivaron esta reforma, el procedimiento empleado, así como los distintos pasos relativos a su elaboración... proceden del A.G.S. Secretaría y Superintendencia de Hacienda. Leg. 70, así como del A.H.N. Consejos, Leg. 22.299.

2 Novísima Recopilación de las Leyes de España. Madrid, 1976. Libro III, Título III, Ley I, p. 13. 
"No obstante la abolición de los fueros de aquel Reino, y los repetidos especiales encargos hechos a los tribunales para que no permitan su observancia, así Orihuela como Alicante han continuado en la exacción de arbitrios y su gobierno, manejando sin orden sus regidores capitulares y dependientes los que han llamado propios, con perjuicio del público, sin la debida cuenta y razón, y cometiendo otros excesos perjudiciales al público en contravención de las Reales Resoluciones" ${ }^{3}$.

\section{ANTECEDENTES}

En cierto modo, puede decirse que la reforma empezó a gestarse como consecuencia de la carta que en 4 de diciembre de 1743 dirigió Antonio de Heredia ${ }^{4}$ a Miguel Ric y Ejea", y en la cual le informaba sobre "la urgencia y necesidad que había de remedio en esta ciudad... en cuanto al gobierno, recaudo, administración y distribución de los caudales públicos"'6.

Esta llamada de atención, unida a la existencia de unos precedentes como las pesquisas de 1712 y 1726 , frustradas "por el artificio y cautela de los regidores de esta ciudad", movieron a Miguel Ric a promover ante el Consejo la realización de una nueva pesquisa?.

La pesquisa se llevó a efecto durante el año 1794 y le fue encargada a José Javier de Solórzano ${ }^{8}$, quien como juez pesquisidor hizo las preceptivas averiguaciones, emitiendo finalmente un informe.

El panorama con que se encontró Solórzano en Orihuela no podía ser más desolador, hallando que "ha estado el gobierno de esta Ciudad el más confuso e inordinado, los libros de acuerdos sin método y firmas, con huecos, añadidos, sobrepuestos y otros defectos sustanciales; los libramientos sin formalidad y usando de los caudales públicos a su arbitrio y utilidad, sirviéndoles de instrumento el subsíndico Antonio Jiménez. La distribución de caudales públicos se ignora en muchas partes, y lo mismo sucede con el producto de dehesas. Las cuentas que ha reconocido el Juez ${ }^{9}$ no merecen el concepto de tales pues en la más mínima parte no se halla la más remota formalidad. Del producto de los herbajes se ignora. En el pósito ha sido absoluto el depositario, al que le han permitido y permiten diferentes fraudes y lucros, y otros que parece cedían

3 A.G.S. Secretaría y Superintendencia de Hacienda, Leg. 70. Dictamen de la Real Junta para el nuevo gobierno de Alicante, 30 de julio de 1746.

4 Antonio de Heredia Bazán fue corregidor de Orihuela de 1719 a 1721.

5 Sobre la trayectoria de Miguel Ric Ejea vid. P. MOLAS RIBALTA: "Las Audiencias borbónicas de la Corona de Aragón. Aportación a su estudio", en Estudis, 5 (1976), pp. 59-124, esp. 100-102.

6 A.G.S. Secretaría y Superintendencia de Hacienda, Leg. 70: Informe de la Real Junta de Orihuela, 30 de julio de 1746 .

7 Un estudio sobre la práctica de la pesquisa basado en un caso de la segunda mitad del siglo XVIII, el origen jurídico de la misma, así como una caracterización general de la pesquisa en relación con la visita y la residencia puede verse en GONZALEZ ALONSO, Benjamín: "Control y responsabilidad de los oficiales reales: notas en torno a una pesquisa del siglo XVIXI", en Sobre el Estado y la Administración de la Corona de Castilla en el Antiguo Régimen, Madrid, 1981, pp. 141-202. Los diferentes elementos caracterizadores de una pesquisa aparecen sistematizados, así mismo, en el modelo descrito en las pp. 150-151.

8 Solórzano era ministro honorario de la Audiencia de Sevilla.

9 Se refiere a Solórzano. 
en beneficio del pósito no aparecen; ha estado y está sin libro ni formalidad. No se han vigilado los abastos públicos ni observado igualdad en el repartimiento de contribuciones ni alojamiento de soldados; oponiéndose en lo más a sus mismos estatutos antiguos..." 10 .

Vista la gravedad de los hechos, Felipe V se pronunció positivamente sobre la necesidad de formar una Junta que estudiara los hechos y propusiera soluciones. Dicha Junta estaría presidida por el marqués de Lara y compuesta por Andrés de Bruna, Juan Antonio Samaniego y Diego de Sierra, todos ellos miembros del Consejo de Castilla"1, así como Miguel Ric y Ejea que actuaría como fiscal.

La Junta tendría como misión elaborar un plan de gobierno para la ciudad de Orihuela "ajustado a las leyes de Castilla", y en el que se señalarían los gastos anuales que podría realizar el municipio, la naturaleza y estado de los propios, los arbitrios que deberían suprimirse por ser gravosos al común de vecinos, así como cualquier otra providencia que juzgara de interés para "la Causa pública". Además de estas nuevas normas de gobierno, debería ocuparse de imponer a los regidores y escribano, que se hubieran visto envueltos en la pesquisa realizada por Solórzano, castigos correspondientes a los delitos cometidos, consultándolo con el rey antes de ponerlo en ejecución ${ }^{12}$.

Para llevar a cabo la primera tarea -dotación- la Junta pidió informes a José Javier de Solórzano, así como a la propia ciudad de Orihuela ${ }^{13}$, sobre la naturaleza y cuantía de los gastos e ingresos anuales ${ }^{14}$. Tanto Solórzano como la Ciudad cumplieron puntualmente la misión que se les había encomendado ${ }^{15}$.

\section{EL PARECER DEL FISCAL MIGUEL RIC Y EJEA}

Cuando la Junta tuvo en su poder todos los informes solicitados para el mejor conocimiento de los hechos, se remitieron al fiscal, Miguel Ric y Ejea, quien evacuó su informe el 29 de diciembre de 1745 manifestando que los ingresos del municipio oriolano, pese a ser considerados producto de propios, procedían mayoritariamente de arbitrios ${ }^{16}$. Las fuentes de dichos ingresos eran: yerbas de la redonda, albalán de

10 A.G.S. Secretaría y Superintendencia de Hacienda, Leg. 70: g, 30 de julio de 1746.

11 Tras la muerte de Andrés de Bruna ocuparía su puesto Pedro Colón.

12 En resumen, tres eran las tareas que se encomendaban a la Junta: dotación económica de la ciudad, establecimiento de nuevo gobierno conforme a las leyes castellanas y castigo de los excesos cometidos por sus regidores.

13 La Ciudad debía nombrar dos diputados, quienes, junto al procurador general, serían los encargados de elaborar un plan en el que se hiciera constar la situación económica del municipio.

14 Las cargas que debía satisfacer anualmente el ayuntamiento eran las correspondientes a censos, así como los gastos ordinarios y extraordinarios. Los ingresos estaban en función de lo que produjesen los propios, arbitrios, censos, así como otras rentas que percibiera la Ciudad.

15 "Los diputados y procurador general (...) juntos con el juez pesquisidor Solórzano ejecutaron cumplidamente el informe de todo, y separadamente lo practicó el dicho juez, y posteriormente el mismo cuerpo de (...) ciudad, habiéndoseles dado vista, a su instancia, del informe público y plan remitido por sus diputados y procurador general y D. José de Solórzano" (A.G.S. Secretaría y Superintendencia de Hacienda, Leg. 70. Dictamen de la Real Junta para el nuevo gobierno de Orihuela, 30 de julio de 1746).

16 A.H.N. Consejos. Leg. 22.299. $2^{"}$ pieza, ff. 54-60v. Informe del fiscal, Miguel Ric y Ejea, 29 de diciembre de 1745 . 
molienda ${ }^{17}$, aguas saladas, molino, estanco del jabón, correduría, estanco del vino, sosa y barrilla, yerbas del monte, peso y romana, pescado y cuatro casas, censos y útiles de matadero; todos ellos rendían anualmente unas 15.960 libras.

Pese a obtener la Ciudad una cantidad importante de ingresos, sus deudas ascendían a 7.411 libras, lo que hace suponer fuertes dispendios y apropiación indebida de caudales, ya que en el plan elaborado por la Ciudad a petición de la Junta se juzgaron suficientes 9.361 pesos/año ${ }^{18}$ para todos los gastos, tanto ordinarios como extraordinarios.

Para regular las fuentes de ingresos municipales en lo sucesivo, mejorar la "administración, distribución y seguridad" de los mismos, moderar los gastos, "acabar con los usos forales", lograr una baja de los intereses de los censos, etc., el fiscal propuso la adopción de una serie de medidas como limitar el gasto en las exequias reales a 100 pesos; reducir el que generaba la práctica de alojamientos, pagando únicamente el costo de la comida -que no debería exceder las $6 \mathrm{Lb}-{ }^{19}$; no efectuar obras públicas importantes sin consultarlo antes con el Consejo...

Estimaba necesario, así mismo, construir un nuevo pósito por haber serias deficiencias en el existente, razón por la cual en algunas épocas del año debían alquilarse casas para cambiar el trigo de sitio y evitar así que éste se pudriera ${ }^{20}$. En la construcción del pósito se podrían gastar 2.000 de las 5.000 libras que éste presentaba de superávit. En este caso el edificio que ocupaba dicho pósito podría destinarse a cárcel, una vez reparado y fortificado. Los gastos ocasionados por la restauración se cubrirían con la venta de la cárcel existente.

Los 3.000 pesos sobrantes de la dotación del pósito podrían destinarse a redención de censos, así como los créditos a favor de la Ciudad, el dinero que por el arbitrio del matadero hubiera recibido de más la Real Hacienda y los 1.500 pesos que los regidores cobraron al regreso de la tropa de Orán.

El fiscal estimaba conveniente la implantación de un Contador, así como el restablecimiento de la Abogacía Patrimonial ${ }^{21}$.

Miguel Ric, al igual que años antes -hacia 1716- el presidente de la Chancillería de Valencia, Pedro de Larreategui, "consideraba excesiva y costosa la presencia de militares" al frente del corregimiento oriolano ${ }^{22}$, por lo que proponía extinguir los

17 Por albalán de molienda se entiende la cantidad que debían abonar quienes molieran cereal en el término jurisdiccional de la ciudad, y que gravaba a razón de 4 drs./barchilla de trigo y 2 drs./barchilla de cebada y panizo.

18 Un peso equivale a una libra (H. KAMEN: La guerra de Sucesión en España. Barcelona, 1974, p. 428$)$.

19 Se suspendía, por tanto, la paga de dietas a los capitulares, procurador general, escribano y portero.

20 Sobre la ubicación del pósito, VILAR, J. B.: Orihuela, una ciudad valenciana en la España moderna, Murcia, 1981. Vol. I, pp. 69-70.

21 La abogacía patrimonial contaría con una dotación de 100 lbs. pagaderas por mitad entre la ciudad y lugares de su gobernación.

22 GIMENEZ LOPEZ, E.: "El establecimiento del poder territorial en Valencia tras la Nueva Planta borbónica”, en Estudis, 13 (1988), pp. 225-226. 
cargos de gobernador y alcalde mayor ${ }^{23}$ y convertir a Orihuela en corregimiento de letras ${ }^{24}$.

\section{DICTAMEN DE LA JUNTA}

El dictamen de la Junta, tras analizar los informes del fiscal, Ciudad, juez pesquisidor, etc., se adentraba en los tres campos que le habían sido encomendados: dotación económica de la ciudad, reglas de nuevo gobierno y castigo a los inculpados por la pesquisa.

\section{Dotación económica}

Paso previo a la distribución de los ingresos municipales fue conocer cuántos eran y de dónde procedían. En este sentido la Junta señalaba que pese a conceptuarse como propios numerosos efectos, en realidad sólo la pescadería, el molino, los censos y el más dudoso de peso y romana lo eran; los que juntos producían 3.370 libras anuales.

\section{INGRESOS ANUALES POR PROPIOS}

\begin{tabular}{|c|c|}
\hline Concepto & Cuantía que produce \\
\hline Pescadería y 4 casas & 913 lbs. \\
\hline Molino & 1.433 \\
\hline Censos & 465 " \\
\hline Peso y romana & 559 \\
\hline TOTAL & 3.370 Ibs. \\
\hline
\end{tabular}

Aunque no tuviera más propios que los arriba señalados, con el fin de que la Ciudad pudiera subvenir a sus gastos -ordinarios, extraordinarios y redención de censos- se le asignaban una serie de arbitrios ${ }^{25}$.

23 El establecimiento de corregidor de letras no venía motivado por una desacertada actuación del gobernador y alcalde mayor, sino exclusivamente para reducir gastos.

24 Ténganse presentes las polémicas suscitadas a lo largo del siglo entre partidarios de la presencia militar en cargos de gobierno y defensores de las tesis civilistas. Cfr. GIMENEZ LOPEZ, E.: Op. cit. pp. 217-239.

25 Arbitrios que ya venía aplicando previamente la Ciudad. 


\section{ARBITRIOS ASIGNADOS}

\begin{tabular}{|c|c|}
\hline Concepto & Cuantía que produce anualmente \\
\hline Yerbas & $706 \mathrm{lbs}$. \\
\hline Aguas saladas 26 & $16 \cdots$ \\
\hline Jabón & $500 “$ \\
\hline Correduría & $750 “$ \\
\hline Sosa y barrilla & 304 “ \\
\hline Vino & 506 “ \\
\hline Yerbas de monte & $113 ،$ \\
\hline Derecho de molienda & $3.648 \cdots$ \\
\hline TOTAL & $6.543 \mathrm{lbs}$. \\
\hline
\end{tabular}

La cantidad total con que quedaba dotada la ciudad de Orihuela para los tres tipos de gastos respondía a la suma de propios y arbitrios, los que juntos completaban la cantidad de 9.913 libras.

Una vez consignados los ingresos a percibir por el municipio, la Junta fijaba cuántos habían de ser los gastos a acometer y por qué conceptos. La primera partida, y la más importante cuantitativamente, iba dirigida a gastos ordinarios. Entraban dentro de este bloque las cantidades destinadas a satisfacer el salario del personal del ayuntamiento (corregidor, alcalde mayor, regidores, escribano, depositario...), a sufragar las principales festividades (Corpus, Santas Justa y Rufina, Viernes Santo, etc.), a la asistencia de los pobres (limosnas), dotación a la Universidad, etc. ${ }^{27}$.

Además de los gastos ordinarios estaban los extraordinarios, difíciles de calcular debido a su naturaleza irregular e imprevisible. Para acometerlos se asignaba la cantidad de 1.000 lbs., encareciéndose repetidamente la no realización de gastos superfluos ${ }^{28 .}$

La cantidad total señalada para gastos ordinarios y extraordinarios era de 6.647 lbs., cantidad que debería extraerse de una serie de conceptos: propios y arbitrios.

26 Bajo tal concepto se incluía el producto de unos bebederos para el ganado.

27 Para el desarrollo completo de las cantidades destinadas a gastos ordinarios, así como los diferentes conceptos que componen dicha partida, vid. Anexo I.

28 El fiscal, Miguel Ric, estimaba que la reducción de los gastos extraordinarios a $1.000 \mathrm{lbs}$. quedaba plenamente justificada por cuanto desde ese momento quedaban "prohibidas las gratificaciones de personas de graduación que transiten por aquella ciudad, las de los oficiales generales y coroneles, las que se hacían a mujeres que parían 2 de un parto, a los que mataban gorriones y todas las demás de esta clase" (A.H.N. Consejos. Leg. 22.299. Pieza 2", f. 59v. Informe del fiscal, 29 de diciembre de 1745). 


\section{PROPIOS Y ARBITRIOS ASIGNADOS PARA EL PAGO DE GASTOS ORDINARIOS Y EXTRAORDINARIOS}

\begin{tabular}{|c|c|}
\hline Concepto & Cantidad que rendía \\
\hline Albalán de molienda & 3.648 lbs. \\
\hline Molino & 1.433 \\
\hline Pescado y 4 casas & 913 \\
\hline Yerbas & 706 \\
\hline TOTAL & $6.700 \mathrm{lbs}$. \\
\hline
\end{tabular}

Para la segunda clase de gastos, esto es, pago de atrasos y luición de censos se destinaba el producto de una serie de propios y arbitrios:

\section{PROPIOS Y ARBITRIOS ASIGNADOS AL ARCA DE ACREEDORES}

\begin{tabular}{|c|c|}
\hline Concepto & Cantidad producida anualmente \\
\hline Aguas saladas & $16 \mathrm{lbs}$. \\
\hline Jabón & $500 \cdots$ \\
\hline Correduría & $750 \lll$ \\
\hline Peso y romana & $559 \lll$ \\
\hline Vino & $506 ،$ \\
\hline Sosa y barilla & 304 “ \\
\hline Yerbas del monte & $113 \lll$ \\
\hline Censos & 465 ، \\
\hline TOTAL & $3.213 \mathrm{lbs}$ \\
\hline
\end{tabular}

Además de las 3.213 lbs. por los conceptos reseñados, deberían aplicarse al arca de acreedores los 1.500 pesos que recibieron los regidores al regreso de la tropa de Orán, las $3.000 \mathrm{lbs}$. sobrantes de la dotación del pósito ${ }^{29}$ y "el caudal existente y depositado del producto de todos los arbitrios de matadero perteneciente a la Ciudad", así como lo que hubiera percibido de más la Real Hacienda por dichos efectos. Finalmente, se asignaba a la Joya de acreedores ${ }^{30}$ todo cuanto se le debiese a la Ciudad por cualquier concepto o razón.

Con estas dotaciones a ambas arcas se pretendían dos cosas:

a) Que con el efectivo ingresado en el arca destinada a gastos ordinarios y extraordinarios se mantuviese la administración de la ciudad al corriente durante todo el año; y

b) Que con el fondo establecido en la segunda arca o Joya de acreedores se

29 Recuérdese que de las 5.000 lbs. de que disponía el pósito, 2.000 debían aplicarse a la construcción del nuevo edificio.

30 Por Joya de acreedores era conocido un fondo monetario que debía servir para el pago y cobro de deudas de cualquier tipo que afectasen a la Ciudad. 
Ilegase a eliminar el déficit de la hacienda municipal (pago de censos y otras deudas contraídas) para que, una vez subsanado éste, pudieran cesar los arbitrios asignados para cubrir dicho déficit, lo que redundaría en beneficio del común de vecinos que vería desaparecer una serie de cargas como las que recaían sobre el vino, sosa y barrilla, yerbas del monte... ${ }^{31}$.

Tras elaborar el plan de dotación de la ciudad, y observando que con los propios y arbitrios que iban asignados podían satisfacerse todos los gastos que surgieran, la Junta estimó oportuno abolir los arbitrios del matadero ${ }^{32}$ por cuanto gravaban un alimento tan necesario para la población como la carne; de éstos sólo el "útil del sebo" debía subsistir y aplicarse como dotación perpetua a la Casa de Misericordia que fundara el obispo Juan Elías Gómez de Terán ${ }^{33}$. A más de los útiles del sebo se debían entregar, como dotación a dicha Casa de Misericordia, tres despojos de carnero diarios ${ }^{34}$.

\section{Reglas de nuevo gobierno}

La Junta hubo de regular el funcionamiento del municipio oriolano no sólo a nivel económico, sino también político. Para la reforma de este último aspecto consideró necesaria la adopción de una serie de medidas como:

1) La reducción del número de regidores de doce a ocho, los cuales no podrían percibir más compensación económica por sus tareas que el salario que tuvieran asignado. Esta reducción se iría produciendo conforme fueran vacando las cuatro primeras regidurías.

2) Desaparición del cargo de alférez mayor ${ }^{35}$.

3) Establecimiento de un Contador encargado de verificar la correcta aplicación de las "nuevas reglas de gobierno" 36 .

4) Creación de la abogacía patrimonial para vigilancia de cuantas cuestiones afectasen a regalías y "causa pública".

5) Formación de Archivo municipal. La Junta recomendaba que "el Archivo de la ciudad se componga, ordenen sus papeles, inventariándolos, y haga tres llaves, que tenga el gobernador una, otra el regidor decano y otra el escribano de ayuntamiento; que se tenga libro formal para los acuerdos y se extiendan sin salir del Ayuntamiento, dejándolo firmado" 37 .

31 Se indicaba, sin embargo, que alguno de los arbitrios menos gravosos para el común podrían subsistir, aun después de desaparecer las deudas municipales, pasando a engrosar el caudal destinado a gastos ordinarios y extraordinarios.

32 Los arbitrios de matadero rendían más de 6.000 lbs. anuales.

33 Los útiles del sebo ascendían a unas 400 ó $500 \mathrm{lbs}$. anuales.

34 Dichos despojos comprendían "vientre, livianos, pies, hígado, cabeza y piel".

35 El cargo de alférez mayor había sido comprado por Ignacio Sánchez Bellmont en 1745. (A.H.N. Consejos, Leg. 18.345. Sobre el número de regidores, fechas de sus títulos, días de las posesiones).

36 La misión del contador sería vigilar la recaudación, distribución y administración de los efectos asignados a las dos arcas. El modelo de Contaduría a copiar sería el de Alicante.

37 A.G.S. Secretaría y Superintendencia de Hacienda. Leg. 70. Dictamen de la Junta para el nueve gobierno de Alicante, 30 de julio del 746. 
Estas medidas, patrocinadas desde las altas esferas de gobierno, se llevaron rápidamente a efecto, pues, en 1750, entre las disposiciones adoptadas por el cabildo municipal a primeros de año figuraba encuadernar los libros de remates, actas capitulares, protocolos... ${ }^{38}$.

6) Establecimiento de Joya de acreedores.

7) Construcción de dos arcas donde depositar los ingresos municipales: una dedicada a satisfacer los gastos ordinarios y extraordinarios y otra para la Joya de acreedores. Dichas arcas serían de madera, "con los hierros correspondientes para su fortaleza", y estarían dotadas de cuatro cerraduras con sus respectivas llaves; cada una de las cuales sería guardada por un individuo distinto, de tal manera que no podría abrirse el arca de no contar con la concurrencia de los cuatro sujetos provistos de llave $^{39}$. Estas arcas se ubicarían en casa del corregidor para mayor seguridad.

Cada una de las arcas dispondría de un libro donde el escribano anotaría por una parte las partidas de ingresos y por otra la de gastos, así como la razón de las mismas, con lo que podría conocerse en cualquier momento la disponibilidad de fondos existentes en las arcas municipales.

8) Fijar unas reglas que habrían de observarse en los arrendamientos de rentas municipales. Así, al formalizarse el arrendamiento de cualesquiera de dichas rentas, contador y depositario debían ser informados -en el plazo de tres días- de la cantidad en que había sido rematada, arca en que había de ingresarse su valor y los plazos en que se abonaría, ya que el depositario era el encargado de realizar los cobros.

El arrendatario debía presentar fiadores que lo avalasen antes de hacerse cargo de la renta municipal en cuestión. Regidores y depositario eran los encargados de descubrir la solvencia de dichas fianzas por cuanto ellos respondían en última instancia del cobro de la cantidad en que se hubiera rematado la renta arrendada ${ }^{40}$.

9) Señalar las atribuciones del Depositario, quien debería estar al corriente del dinero que se ingresaba y extraía de las arcas municipales, para lo cual habría de llevar una contabilidad de las entradas y salidas, así como extender recibos -intervenidos por el Contador- en los que se indicara de los efectos de cuál de las arcas se trataba.

10) Definir el sistema de pagos. La Ciudad no podría satisfacer ningún pago que no hubiera sido aprobado previamente por el Ayuntamiento, así como hacer libramientos sin consultar antes a la Contaduría y constar haber fondos. De suceder esto -falta de caudal en las arcas- no podría abonarse cantidad alguna, razón por la cual estimaba agudamente la Junta que "por su propia conveniencia y lucimiento, cuidarán los

38 A.M.O. Actas capitulares. Lib. 198, 1750-1I-14, f. 26v. También 1750-IV-11, ff. $73 v-74$.

39 Las Ilaves se repartían de la siguiente manera: la primera correspondía al corregidor, y en su ausencia al alcalde mayor o quien administrase la justicia; la segunda a un diputado regidor de arcas nombrado por la Ciudad a primeros de año, y en su ausencia al regidor que aquél considerara de su mayor confianza, con aprobación de la Ciudad; la tercera quedaría en manos del contador de la ciudad o la persona que le sucediera en su empleo, sustituyéndolo en caso necesario el escribano de Ayuntamiento, quien debía estar presente siempre que se abrieran las arcas; la cuarta la tendría el depositario de rentas de la Ciudad, siendo sustituido en caso de impedimento o ausencia por la persona que él eligiese.

40 Un ejemplo del interés con que seguían los regidores la presentación de fianzas, así como la solvencia de las mismas, puede verse en las actas capitulares del año 1750 por lo que respecta a las presentadas por el corregidor, Marqués de León, y los depositarios del pósito y del real equivalente. Vid. A.M.O. Actas capitulares. Lib. 198, 1750-I-10; 1750-IV-18, 1750-V-30, 1750-VI-9, 1750-VI-25. 
regidores que las rentas se recauden y cobren a su debido tiempo y plazos, para llevar solventes sus salarios y la satisfacción de las obligaciones del común" "4t.

Los salarios de los regidores se abonarían de una vez a final de año ${ }^{42}$; los del corregidor, alcalde mayor y demás cargos municipales se pagarían por tercias.

11) Supervisar el funcionamiento de las arcas municipales. A final de cada mes debería hacerse una comprobación del caudal existente en las arcas bajo supervisión de los "cuatro llaveros" y el escribano, quien haría una relación de la cantidad presente a fin del mes anterior, así como de las entradas y salidas del corriente; relación que habría de cotejarse con la realizada por el Contador en el mismo intervalo. Esta comprobación mensual se denominaría "hacimiento de arcas" y en la misma podría estar presente cualquier persona interesada en observar dicha verificación para que a todos constare la legalidad de la operación.

Finalizado el año se efectuaría una comprobación semejante a la llevada a cabo a fin de cada mes para asegurarse sobre lo correcto del procedimiento seguido durante todo el período.

Aunque anualmente debían verificarse las operaciones efectuadas en las arcas, cada tres años se remitiría al Consejo el total de "las cuentas originales con los recados de cargo y data de su respectivo trienio" para que fueran analizadas y se comprobase si todo había sido realizado correctamente.

Todas estas disposiciones son prueba de la poca libertad de acción que se dejaba al ayuntamiento oriolano. Todo era regulado con minuciosidad permitiendo un control total del municipio en el campo tanto económico como político (se creaban nuevos empleos, se suprimían otros; ingresos y gastos eran establecidos rigurosamente...). El dirigismo estatal imperaba, por tanto, a todos los niveles en el proyecto de reforma propuesto por la Junta.

\section{Condena a los regidores}

Por último la Junta se manifestaba sobre los regidores oriolanos y el castigo que a su juicio merecían algunos de ellos por su actuación. Los capitulares que aparecían inculpados eran José Balaguer, Juan de Otazo, Francisco Ruiz Villafranca y Antonio Pérez Meca, los cuales deberían ser suspendidos de sus oficios por cuatro años ${ }^{43}$. Asimismo, Julián Risueño, escribano del Ayuntamiento que había tenido una en el desempeño de su tarea y a quien se tildaba de "ignorante y perezoso", tendría que abandonar la escribanía y nombrar teniente que la regentase.

Tanto regidores como escribano podrían apelar, no obstante, ante la sala del crimen de la Audiencia de Valencia.

41 Idem nota 37.

42 Para ello deberían asistir, como mínimo, al 75 por ciento de los cabildos convocados salvo impedimento notorio (enfermedad, haber tenido que salir de la ciudad a realizar alguna misión encomendada por el Ayuntamiento...).

43 El fiscal proponía que José Balaguer fuera privado de oficio mientras los otros tres eran suspendidos por cuatro años. 


\section{EL INFORME DE GABRIEL ORTIZ}

Tras practicar la Junta su informe, éste le fue remitido, por orden del rey, a Gabriel Ortiz para que señalase reservadamente qué puntos de los indicados por aquélla consideraba que cabía establecer y cuáles modificar o abandonar ${ }^{44}$.

Ortiz valoraba muy positivamente la "madurez, reflexión y discreción" mostrada por la Junta en su dictamen; no obstante, consideraba oportuno hacer algunas matizaciones ${ }^{45}$.

En cuanto a dotación, Gabriel Ortiz se quejaba de que la Junta sólo había contemplado la posibilidad de que los arbitrios fueran arrendados ${ }^{46}$. La inexistencia de arrendatarios, en ocasiones, requería de otras vías de actuación; la administración por los propios regidores podía ser una alternativa, pero la sospecha de que éstos sólo buscasen su propio beneficio, gastando más de lo que produjeran dichos efectos, hacía a Ortiz desistir de su aplicación. En cambio, sí consideraba una alternativa a la falta de arrendatarios la designación de un administrador solvente para que se encargase de la renta en cuestión. Este debería ingresar todos los meses las cantidades recaudadas en el arca correspondiente y rendir cuentas a fin de año de la labor realizada.

Respecto al establecimiento de nuevo gobierno Ortiz era partidario de que la elaboración de las nuevas Ordenanzas se encargase a José Javier de Solórzano por la brillantez de su actuación durante la pesquisa ${ }^{47}$.

Tocante a la última cuestión -excesos cometidos por los capitulares-Ortiz prefería seguir el dictamen del fiscal ${ }^{48}$ : privar a Balaguer de la regiduría que ostentaba. También discrepaba de la Junta en lo relativo al órgano de apelación de los regidores inculpados, pues mientras ésta consideraba que debía ser la Real Audiencia, Ortiz proponía que fuera Solórzano, buen conocedor de esas cuestiones, lográndose con tal procedimiento un ahorro notable de tiempo.

Asimismo debía encargarse a Solórzano la supervisión de las obras a realizar en el pósito y cárcel, mientras de no continuar éste en la ciudad se encomendaría al corregidor y alcalde mayor, mostrando nuevamente su recelo por que se ocuparan de ello los regidores.

\section{DECISION FINAL: LOS DECRETOS DE 4 DE JULIO DE 1747}

Tras recibir y estudiar los anteriores informes, la decisión real se materializó en

44 A.G.S. Secretaria y Superintendencia de Hacienda. Leg. 70. El Marqués de la Ensenada a D. Gabriel Ortiz, 13 de agosto de 1746.

45 A.G.S. Secretaría y Superintendencia de Hacienda. Leg. 70. Gabriel Ortiz al Marqués de la Ensenada. 16 de septiembre de 1746.

46 Era el caso más frecuente, de ahí que la Junta no plantease otra posibilidad.

47 También en el punto de elaboración de Estatutos se ponía de manifiesto el recelo que sentía Ortiz ante la actuación de los regidores, a quienes no se atrevía a conferir dicha planificación "por el tedio con que miran aquellos naturales las leyes de Castilla, gobierno de sus ciudades e instrucción de excesos y abusos cometidos".

48 Recordemos que el fiscal proponía privación de oficio en tanto que la Junta se conformaba con que fuera suspensión por cuatro años. 
dos decretos con fecha 4 de julio de $1747^{49}$; en uno de ellos se fijaba la dotación económica anual de la ciudad y la obligación de elaborar nuevas Ordenanzas en el plazo de dos meses; en el segundo decreto se detallaban las penas impuestas a capitulares y escribano por su actuación al frente del ayuntamiento.

La intencionalidad que subyace a lo largo de todo el primer decreto pasa inequívocamente por la observancia de las leyes castellanas, a las que se harían constantes alusiones; de ahí que la primera acusación a la ciudad de Orihuela radicaba en la inobservancia de las mismas y haber persistido en el uso de los antiguos fueros en algunos aspectos (arbitrios), lo que había desembocado en perjuicio de los vecinos. La solución a dichos problemas pasaba, naturalmente, por la aplicación de las leyes de Castilla; para ello deberían redactarse unas nuevas Ordenanzas. En Ia elaboración de las mismas habrían de intervenir cuatro regidores, el abogado de la Ciudad y otro nombrado por el corregidor, quien asimismo debería asistir para contribuir a su redacción.

Tras ser confeccionadas, las Ordenanzas habrían de presentarse ante los capitulares, quienes, reunidos en pleno, darían su opinión sobre las mismas ${ }^{50}$. Posteriormente se remitirían al Consejo, que sería el encargado de pasarlas al rey para su aprobación final.

Además de las ordenanzas de la ciudad, en el ayuntamiento deberían figurar las leyes de Castilla para poder acudir a ellas y consultarlas siempre que surgiera alguna duda.

Para cubrir los gastos municipales se la dotaba con 9.912 libras procedentes de los propios y arbitrios señalados más arriba, los cuales quedaban "libres perpetuamente del real valimiento por mitad de arbitrios" ${ }^{51}$. Además se le concedía una moratoria por seis años en el pago a los censalistas de las cantidades que se les adeudaban, debiendo abonárseles en ese período únicamente los intereses a razón del 3 por ciento y se mantenía la dotación a la Casa de Misericordia, como se señaló en su momento ${ }^{52}$.

Por último, se encomendaba a José Javier de Solórzano la aplicación de las nuevas Ordenanzas, nombrándosele en el interín corregidor de Orihuela. No obstante, sobre el establecimiento permanente de corregimiento de letras en dicha ciudad no se decidía nada, dejándose para más adelante la toma de tan importante decisión ${ }^{53}$.

El segundo decreto dado por Fernando VI fijaba cuatro años de suspensión a los regidores José Balaguer, Juan de Otazo, Francisco Ruiz Villafranca y Antonio Pérez Meca por la mala administración municipal y fraudulento manejo de los caudales públicos. Julián Risueño, escribano del ayuntamiento, era apartado perpetuamente de dicha escribanía, aunque se le permitía nombrar teniente.

49 La idea de los dos decretos -uno por lo que respecta a dotación y establecimiento de nuevas Ordenanzas para la ciudad, y otro en que se condenara la actuación de capitulares y escribano- había surgido del gobernador del Consejo. (A.G.S. Secretaría y Superintendencia de Hacienda. Leg. 70, Gaspar, obispo de Oviedo al Marqués de la Ensenada, 21 de mayo de 1747).

50 Se concedía un plazo de 60 días para su redacción.

51 También se perdonaba a la Ciudad cuanto debiera a la hacienda regia por dicha causa.

52 Véase más atrás.

53 Fernando VI reconocía que la conducta del Marqués de León y su alcalde mayor había sido satisfactoria, por lo que, al privarle de su cargo y concedérselo a Solórzano, señalaba que le otorgaría otro conforme a sus méritos. 
Sin embargo, si alguno de ellos -regidor o escribano- se sentía lesionado en sus derechos podía recurrir a la Audiencia valenciana ${ }^{54}$.

\section{SECUELAS: LA PROTESTA DEL CORREGIDOR Y ALCALDE MAYOR}

Como hemos ido viendo, todos aquellos que emitían informes sobre Orihuela y sus necesidades coincidían en un punto: la modificación del corregimiento militar para reducirlo bien a corregimiento de letras, bien de capa y espada. Cualesquiera de estas dos soluciones presentaba un inconveniente ¿qué hacer con los actuales corregidor y alcalde mayor?

Ni el Marqués de León ni Francisco Miguel Navarro aparecían con culpabilidad alguna derivada de la pesquisa y por tanto no parecía justo privarles de su empleo, tanto menos en una ocasión como ésta, en la que varios regidores eran suspendidos por cuatro años como consecuencia de su negativa actuación al frente del Ayuntamiento. Cualquiera que no estuviera al corriente del asunto podría pensar que aquéllos eran cesados por idénticos motivos.

Tanto por la razón aducida como por el hecho concreto de verse privados de sus respectivos empleos, la puesta en práctica de tal medida - cese del Marqués de León y de Navarro- motivó una serie de memoriales por parte de los involucrados, como también de la ciudad de Orihuela, solicitando su permanencia en los puestos que desempeñaban.

En la temprana fecha del 15 de julio, corregidor y alcalde mayor recurrían al Marqués de la Ensenada para que intercediera en su favor ante el rey. Al mismo tiempo manifestaban su desconcierto por la destitución de sus empleos, que atribuían a la malicia de dos capitulares y al propio Solórzano, quienes pretenderían colocar en el corregimiento a un individuo fácil de manejar. Insistían, asimismo, en que por ser Orihuela zona de frecuente paso de expediciones militares y abarcar su jurisdicción una amplia zona costera - que cabía defender de posibles incursiones enemigas- debía ser un militar quien estuviera al frente del corregimiento.

Señalaban, además, los habituales argumentos referidos a que la privación de empleo repercutiría negativamente sobre ellos por cuanto no habían propiciado con su actuación semejante castigo, a la vez que les dejaba sumidos en la pobreza. Por todo ello, así como por sus méritos y servicios, solicitaban que el rey les permitiera seguir ejerciendo sus respectivos empleos, así como instaurar las nuevas normas de gobierno en Orihuela. En caso contrario podia encargársele a Solórzano este último punto, pero no el corregimiento.

El Marqués de León iba apuntando argumentos que pudieran modificar la actitud del rey respecto al titular del corregimiento. Estos argumentos serán los mismos que esgrimirán diferentes militares a lo largo del siglo y siempre que se intente reducir su protagonismo político.

Nuevamente recurrió el Marqués de León a Ensenada el 19 de julio para que éste intercediera en su favor ante Fernando VI. Sin embargo, en el decreto de 4 de julio el

54 Como puede observarse, Fernando VI recogía en sus decretos las opiniones vertidas por la Junta, en tanto que pasaba por alto las recomendaciones de Gabriel Ortiz. 
rey no se inclinaba claramente por el establecimiento en Orihuela de corregidor de letras, sino que, por el contrario, dejaba su decisión en suspenso ${ }^{55}$. Esta falta de determinación, unida a las protestas del Marqués de León y Francisco Miguel Navarro, sirvió para reavivar la vieja polémica sobre qué tipo de corregimiento era el más beneficioso $\mathrm{y}$, por tanto, se debía establecer o mantener.

En apoyo de la permanencia del corregimiento en manos del Marqués de León - corregimiento militar - se manifestó el capitán general de Valencia, Duque de Caylus, al señalar que Orihuela nunca había sido corregimiento de letras, sino siempre militar ${ }^{56}$, categoría que debía mantener por varias razones: amplitud de la costa marítima, ser frontera con Murcia, tener en su territorio multitud de pueblos que servían de acuartelamiento a la caballería por las condiciones del terreno, abundancia de paja y cebada, etc. ${ }^{57}$.

Sólo unos días más tarde -el 2 de agosto- el duque de Caylus volvía a insistir ante el Marqués de la Ensenada con idénticas razones, adjuntando en esta ocasión el testimonio del escribano Antonio Jiménez, quien exponía que la misma ciudad de Orihuela se mostraba contraria a la implantación de corregidor letrado no sólo por cuestiones de prestigio ${ }^{58}$, sino por los perjuicios que podría producir tal establecimiento al propiciar un aumento de litigios. A este respecto resulta interesante considerar la opinión que la Ciudad tenía sobre el tema y que recogía el escribano en su documento:

"No hay pueblo en España más abundante de personas literatas que éste, tanto que este beneficio le ha incomodado muchas veces. Pues ¿qué convulsiones no ocasionaría introducir en su cabeza las fatales máximas de los letrados si para regidores es inconveniente el serlo? No hay duda que para gobernar lo económico y político de una república que está llena de letrados era mucho más perjudicial; que todo se reduciría al estado gravoso y costoso judicial" 59 .

Como se ha reiterado a lo largo del trabajo, la postura del capitán general estaría siempre del lado de los militares impidiendo, cuando ello fuera posible, que se menoscabase su poder. Dentro de este planteamiento cabe situar el interés del Duque de Caylus por mantener el corregimiento oriolano en manos del Marqués de Léon.

55 Tampoco había unanimidad con respecto a este punto entre los distintos personajes a quienes se había pedido opinión previamente. Así, Miguel Ric era partidario de establecer un corregimiento de letras y la Junta se manifestaba conforme con dicho parecer; sin embargo, el gobernador del Consejo expresaba que de realizarse algún cambio debía ser para pasar a capa y espada.

56 Aunque, efectivamente, nunca había sido corregimiento de letras, sí lo fue de capa y espada con Heredia Bazán (1719-23).

57 A.G.S. Secretaría y Superintendencia de Hacienda. Leg. 70, El Duque de Caylus al Marqués de la Ensenada, 23 de julio de 1747. Los argumentos del Duque de Caylus eran idénticos a los que esgrimió el también capitán general Duque de San Pedro hacia 1721 para impedir la separación de los cargos de corregidor y gobernador militar. Cfr. GIMENEZ LOPEZ, E.: "El establecimiento del poder territorial...", p. 231 .

58 La gradación en importancia de los corregimientos pasaba por el siguiente orden: militar, capa y espada, letrado.

59 A.G.S. Secretaría y Superintendencia de Hacienda. Leg. 70, Testimonio de Antonio Jiménez, 21 de julio de 1747, quien transcribe en este punto la opinión manifestada por la Ciudad en el segundo proyecto de reforma que remitió al Consejo. 
Las instancias del Duque de Caylus ante el rey movieron al Marqués de la Ensenada a pedir la opinión del gobernador del Consejo, quien respondió el 7 de agosto expresando no ser suficientes los motivos aducidos por el capitán general de Valencia para que subsistiera en Orihuela el corregimiento militar, ya que:

"Acomodar los cuarteles de la caballería no es tan dificultosa ciencia que no la alcance cualquiera corregidor hábil, y lo dilatado de la Marina en la comprehensión de aquel territorio no pide necesariamente gobernador, pues la experiencia ha manifestado los fáciles insultos de los moros en la costa, sin que el gobernador de Orihuela haya podido remediarlos" ${ }^{60}$.

La postura del gobernador del Consejo era, por tanto, totalmente contraria a que prosiguiera el corregimiento militar. Sin embargo, no era totalmente partidario de que pasase a ser de letras "porque en esta clase son muy raros los sujetos que se encuentran para lo que se necesita en Orihuela"; en cambio, si se estableciese corregidor de capa y espada sería "muy fácil acertar la elección en uno de buenos talentos y circunstancias". Además consideraba que por ser Orihuela sede episcopal requería tener al frente de su corregimiento individuo de categoría acorde ${ }^{61}$.

Como se expresaba en el decreto de 4 de julio, José Javier de Solórzano pasó a Orihuela, como corregidor, a practicar el establecimiento de los nuevos Estatutos. Sin embargo, el Marqués de León no se conformó con la negativa y siguió insistiendo ante el rey para que se le restituyese al corregimiento oriolano o, en su defecto, fuera ascendido a brigadier. Continuó patrocinándole, igualmente, el Duque de Caylus, quien de nuevo recurrió ante Fernando VI en diciembre. Tantas súplicas surtieron efecto y cuando en febrero de 1748 Solórzano fue llamado a la Corte, el Marqués de León y Francisco Miguel Navarro volvieron a Orihuela como corregidor y alcalde mayor ${ }^{62}$.

\section{CONCLUSION}

Como ha venido señalándose repetidamente a lo largo de las páginas anteriores, la falta de adecuación de la práctica municipal oriolana a la imperante en Castilla, pese a las continuas recomendaciones de las autoridades centrales, fue el desencadenante de la reforma de 1747. Esta reforma, que abarcaba los aspectos de dotación económica del municipio y establecimiento de nuevas Ordenanzas conforme al patrón castellano, pretendía acabar con la autonomía de que aún disfrutaban las autoridades oriolanas; autonomía que estaba respaldada por el vacío estatutario subsiguiente a 1707 .

La actuación sobre el esquema político-económico del municipio del Bajo Segura, que suponía dicha reforma, se enmarca, sin embargo, dentro de un movimiento mucho más amplio llevado a cabo por Fernando VI desde su llegada al trono y que

60 A.G.S. Secretaría y Superintendencia de Hacienda. Leg. 70, El obispo gobernador del Consejo al Marqués de la Ensenada, 7 de julio de 1747.

61 Vid. GIMENEZ LOPEZ, E.: "El establecimiento del poder territorial...", p. 230.

62 A.G.S. Secretaría y Superintendencia de Hacienda. Leg. 70, El gobernador del Consejo al Marqués de la Ensenada, 20 de febrero de 1749. 
trataba de mejorar la gestión económica de los municipios españoles, viciados muchas veces por las corruptelas y abusos de los regidores ${ }^{63}$.

La preocupación del monarca se ceñía al campo de los propios y arbitrios y a lograr que los ingresos procedentes de dichos conceptos llegaran íntegros a su destino; también a impedir una mala administración de los mismos - malversación de fondos-. De ahí la meticulosa reglamentación de los capítulos de gastos e ingresos municipales a que hacíamos referencia más atrás.

A nivel de la antigua Corona de Aragón, y más concretamente del Reino de Valencia, fueron varias las ciudades que hacia mitad de la década de los 40 sintieron sobre sí, y de forma directa, los efectos de la política municipal fernandina (Alicante, Orihuela, San Felipe). La intervención del poder central iba encaminada en todos estos casos a favorecer la total asimilación del modelo municipal castellano en aquellos ayuntamientos que presentaran aún, pese al tiempo transcurrido desde la abolición de los fueros, residuos de época foral.

Por las mismas fechas que en Orihuela ${ }^{64}$, y teniendo como origen igualmente la práctica de una pesquisa, se proyectó la reforma del ayuntamiento alicantino, las razones de la cual quedan nítidamente expuestas en el decreto de 4 de julio de 1747 donde se indicaba que:

"Las ciudades de Alicante y Orihuela, mal acordadas de estas reales deliberaciones o precisadas acaso por defecto de positivas reglas, han continuado el uso de muchos de sus fueros y estilos antiguos, tanto en la exacción de arbitrios como en otros puntos de su económico gobierno, de donde ha nacido el perjuicio del público, la poca formalidad del cuerpo de Ayuntamiento y sus oficinas y otros excesos irremediables si oportunamente no se ocurriese a su principio y raíz con el más pronto y eficaz remedio, el cual no puede ni debe ser otro que la fundamental práctica de las leyes de Castilla" 65 .

Además de conseguir que en estas ciudades, Alicante y Orihuela, se aplicaran las leyes castellanas, también se pretendía poner orden en las haciendas locales, tantas veces mal administradas, para lo que se procedió a establecer cuáles habían de ser las fuentes de ingresos y cuáles los gastos a acometer:

"Deseando que se establezca en las expresadas ciudades un gobierno seguro y correspondiente al mayor beneficio del público y que se hallen con los fondos convenientes a sus comunes gastos y desempeño de atrasos y redenciones de censos he resuelto dotarlas" 66 .

63 GARCIA MARIN, J. M., "La reconstrucción de la administración territorial y local en la España del siglo XVIII", en Historia de España Ramón Menéndez Pidal, Vol. XXIX, t. 1: La época de los primeros borbones. La nueva monarquia y su posición en Europa (1700-1759). Madrid, 1985, pp. $216-217$.

64 El decreto de 4 de julio comprendía a ambas ciudades.

65 A.G.S. Secretaría y Superintendencia de Hacienda. Leg. 70, Decreto de 4 de julio de 1747.

66 La cantidad que se asignó a la ciudad de Alicante para gastos ordinarios, extraordinarios y redención de censos fue de 11.605 libras. 
Como en el caso oriolano, también los capitulares alicantinos que se habían excedido en el desempeño de sus funciones fueron suspendidos por cuatro años de sus empleos. Los regidores que hubieron de abandonar el ayuntamiento fueron Juan de Rovira, Francisco Berdum y Antonio Colomina.

Parece, según hemos apuntado más arriba, que Orihuela y Alicante no serían Ias únicas ciudades que experimentarían la intervención del poder central en su organización municipal, ya que también San Felipe pasó a tener unas nuevas Ordenanzas hacia $1746^{57}$, medida que probablemente se enmarca dentro del proyecto reformista a que venimos haciendo referencia.

Las medidas adoptadas para la dotación económica de la ciudad de Orihuela resultaron muy beneficiosas a medio plazo, ya que posibilitaron la redención de los censos que ésta se había cargado en diferentes momentos del pasado ${ }^{68}$. Así, de las 61.915 libras que adeudaba hacia 1747 en concepto de censos pasó a 29.500 libras en $1761, \log$ rándose redimir en esos catorce años 9 censos por un valor total de 32.415 libras ${ }^{69}$.

No todas las disposiciones establecidas por los decretos de 4 de julio se implantaron con la misma celeridad. Entre las de más pronto cumplimiento figuraba la dotación económica, la suspensión de regidores, la mayor parte de las normas de gobierno: formación de dos arcas, supresión del cargo de alférez mayor, formación de Archivo municipal...

La que más tardó a adoptarse fue la reducción del número de regidores que el plan de nuevo gobierno prevenía ${ }^{70}$. Esta reducción habría de practicarse cuando se produjesen las cuatro primeras vacantes, por lo que no fue efectiva hasta finales de la década de los setenta.

67 A.H.N. Consejos. Legs. 22.192 y 22.278.

68 Sobre las cantidades que adeudaba la ciudad de Orihuela hacia 1747 por censos, así como los individuos a quienes debían abonarse vid. Anexo II.

69 A.H.N. Consejos. Leg. 23.016. $2^{\text {a }}$ pieza, ff. 1-4. Testimonio dado por Pablo García, 15 de febrero de 1761.

70 Como se recordará, en dicho plan se establecía la reducción de las regidurías de 12 a sólo 8. 
ANEXO I

DOTACION ECONOMICA PARA LA CIUDAD DE ORIHUELA (1747)

\begin{tabular}{|c|c|}
\hline Concepto & Cantidad asignada \\
\hline Corregidor & $1.085 \mathrm{lbs}$. \\
\hline Alcalde mayor & $330^{\prime \prime}$ \\
\hline Regidores (13) & 455 “ \\
\hline Escribano & $200 \cdots$ \\
\hline Depositario & $200 "$ \\
\hline Maceros (4) & $160 \mathrm{lbs}$. \\
\hline Abogado de la ciudad & $15 \cdots$ \\
\hline Capellán & $20 "$ \\
\hline Médico & $6 \cdots$ \\
\hline Cirujano & $4 \cdots$ \\
\hline Fiel de peso y harina & $30 \cdots$ \\
\hline Director del reloj & $11 " 6$ \\
\hline Clarinero & $60 \cdots$ \\
\hline Tablacho & $6 \cdots$ \\
\hline Dulzainero & $20 \cdots$ \\
\hline Agente en Madrid & $30 \cdots$ \\
\hline Abogados en Valencia (2) & $24 \cdots$ \\
\hline Agente en Valencia & $12 "$ \\
\hline Gramática Compañía de Jesús & 230 \\
\hline Impresor & $8 \cdots$ \\
\hline Pregonero & $11 \cdots$ \\
\hline Cera de Secuencias & $10 \cdots$ \\
\hline Fiesta de Santo Tomás & $20 \cdots$ \\
\hline Fiesta de San Vicente & $12 "$ \\
\hline Fiesta de San Gregorio & $10 “$ \\
\hline Cuartel de Almoradí & $16 " 4$ \\
\hline Cuartel de Callosa & $5 \lll$ \\
\hline Sufragio de los reyes & 4 “ \\
\hline Limosna a los pobres de Parroquia & $6 “$ \\
\hline Limosna a San Francisco & $40 " ،$ \\
\hline Limosna a San Juan de Dios & $30 \cdots$ \\
\hline Nueve cátedras y bedel & $200 “$ \\
\hline Fiesta del Corpus & $115 \mathrm{lbs}$. \\
\hline Fiesta de Santa Justa & $115^{\prime}$ \\
\hline Procesión del Viernes Santo & $40 "$ \\
\hline Fiesta de San Pablo & $40 “$ \\
\hline Fiesta de Monserrate & $41 “$ \\
\hline Portes de cartas & 24 " \\
\hline Vestidos de maceros y clarinero & $120 “$ \\
\hline Censos redimibles ya reducidos & $1.852 “$ \\
\hline Censos perpetuos & 25 “ \\
\hline Gastos extraordinarios & $1.000 \cdots$ \\
\hline TOTAL & 6.647 libras \\
\hline
\end{tabular}

Fuente: A.G.S. Secretaría y Superintendencia de Hacienda. Leg. 70. 
ANEXO II

CENSOS QUE ADEUDABA LA CIUDAD DE ORIHUELA HACIA 1747

\begin{tabular}{|c|c|c|c|}
\hline & $N^{0}$ de censos & Individuo o institución & Cantidad \\
\hline & 6 & Colegio de Predicadores & $28.945 \mathrm{lbs}$. \\
\hline & 2 & Clero Iglesia Stas. Justa y Rufina & 7.470 “ \\
\hline & 1 & Marqués de Rafal & $7.500 ،$ \\
\hline & 1 & Juan Rosel y Roda & 7.000 \\
\hline & 2 & José de la Torre & $5.000 ،$ \\
\hline & 1 & Obra pía de Gregorio Badenes & $6.000 ،$ \\
\hline TOTAL & 13 & & $61.915 \mathrm{lbs}$. \\
\hline
\end{tabular}

Fuente: A.H.N. Consejos. Leg. 23.016. Pieza 2", ff. 1-1v. Elaboración propia. 